\title{
CHILDREN'S WORKSHOPS ON AWARENESS OF EARTHEN ARCHITECTURE IN BAASNEERÉ (BURKINA FASO)
}

\author{
C. Mileto, F. Vegas López-Manzanares, L. García-Soriano \\ Universitat Politècnica de València (SPAIN)
}

\begin{abstract}
This text presents the training experience conducted by a research team from Universitat Politècnica de Valencia in January 2018 as part of the "ConBurkina" international development project. The aim of this cooperation project, developed over a two-year period, is to provide support to the Algemesí Solidari association in constructing a secondary school. The work has been organized around different lines, the main one being training and awareness workshops for the local population.

The project has sought to involve local residents and encourage their participation. It is essential for the population as a whole, particularly for the children and young adults who will benefit from this new school, to realise the advantages of earthen architecture over what is known as "French architecture" and the architecture of other schools built of cement blocks and corrugated iron. For this it was essential to organize practical workshops, with an active methodology where these children, future users, could experiment with constructive techniques and the main advantages of the system (experimental activities varying temperatures and ventilation, concept of local production vs. industrial production, etc.).

These workshops have allowed the children of Baasneere to learn about the valorisation of local traditional buildings and techniques, about the appreciation of local natural materials and their properties, and about the importance of the architecture of their village as part of their culture.

All these activities were designed to provide information to the children of Baasneere, increasing their appreciation of their own culture, and in turn empowering the future generations which will be in charge of decision-making in years to come, facing the changes imposed by industry, globalisation and speculation.
\end{abstract}

Keywords: Cooperation, workshops, international development project.

\section{INTRODUCTION}

The "ConBurkina" project (funded by the Centre for Development Cooperation at UPV), was the result of a collaboration between a research group from Universitat Politècnica de València and the Algemesí Solidari association [1].

The town of Baasneere (Burkina Faso) is twinned with the town of Algemesí (Spain), something which has led to several cooperation and exchange activities with the heavy involvement of both town councils and the associations "Algemesí Solidari" (working in Baasneere since 2009) and "BuudBumbu de Bao / Baasneere (A3B)". This lengthy collaboration and relationship between both towns, has led, among other works, to the development of a common project for the construction of a secondary school in the town. For the construction of this school it was decided to carry out a project which takes into consideration the constructive reality of the town of Baasneere.

Architecture is an important part of the cultural expression of any given country, region, or geographical area. The materials used in the construction of a particular area are a basic reflection of its culture. In the specific case of the traditional architecture of Baasneere, these are earthen constructions which are a basic part of local culture both for their remote origins and for their variety and adaptation to their natural and social surroundings. However, as a result of a process derived from the loss of prestige of this traditional earthen architecture, considered to be of poor quality and linked to underdevelopment, it is currently being replaced in some cases by new standardized techniques such as cement and metal sheets.

For this reason, one of the objectives of the ConBurkina project has been to work with the local population, especially the younger members, to promote the valorization of local earthen traditional architecture as an essential part of the culture of Baasneere. 
This project aims to involve the local population in the process for the construction of a school. It is vital for the population in general, and the children and young adults who will enjoy this new school in particular, to understand the advantages of this architecture over what is known as "French architecture" or the architecture of other schools built using cement blocks and metal sheets. This made it essential to organize practical workshops where the population in general and the children and future users could experiment with constructive techniques, and especially with the advantages of the system (differences in temperature and ventilation through experiments and activities, concept of local versus industrial production, etc.).

\section{METHODOLOGY}

The activities proposed share a common methodology, based on active learning and especially using hands ("Learning by doing") [2] where students are able to deduce and acquire theoretical knowledge on a specific subject through their own experience.

Based on the above, pedagogic studies [3] have confirmed that children's brains are far more receptive to experiences and all types of learning. Children are frequently dominated by their subconscious needs to absorb through observation, participation and exploration [4]. Without a doubt, children's education is one of the main tools for bringing about the social changes needed for sustainable development. For this reason, the promotion of a series of early stimulation proposals relating to earth as a construction material contributes to progressively increasing awareness of this architecture among children, as well as its valorization as valid and adaptable for changing needs and adaptation to progress.

Following this process of gradual abstraction of knowledge, these workshops were divided into two parts. The first was a session on the characteristics of earth, which simply examines topics such as colour, texture or composition. The second workshop session incorporated activities focusing on working with earth as a valid construction material, both in traditional and new architecture.

\section{SOCIAL PARTICIPATION ACTIVITIES}

This phase within the ConBurkina project consisted in carrying out social participation activities with the general population, especially the children and young adults who are future students at the school. The workshop organized for the children of Baasneere aimed to promote the value and appreciation of the younger members towards their country's traditional earthen architecture, as well as the constructive techniques for the project of the secondary school which the children will use in the future.

The team from UPV contacted the headmaster of Baasneere primary school to prepare the activity, and it was agreed that approximately 70 children from the CE2 and CM1 years (age 8 and 9) would take part in the workshop. Furthermore, as there were only four people in the UPV team, the help of five 14-year-old students was enlisted to help organize children into groups and translate when necessary. The workshop was held in French, a language which most of the children speak, but some of the more complex points were translated directly by the helpers into Moré to make it easier for the younger children. Although the plan for the workshop had been established before travelling to Burkina Faso, once there, the activities had to be adapted so that they were better-suited to local conditions. Finally, the workshop was developed in two sessions with the different activities described below.

\subsection{First workshop session}

The first workshop session examined the characteristics of earth with a simple study of topics such as colour, texture, or composition. An initial explanation of earth and its variations in shade was provided. For this explanation all the children were gathered in the esplanade outside the primary school which is used as a school playground. 


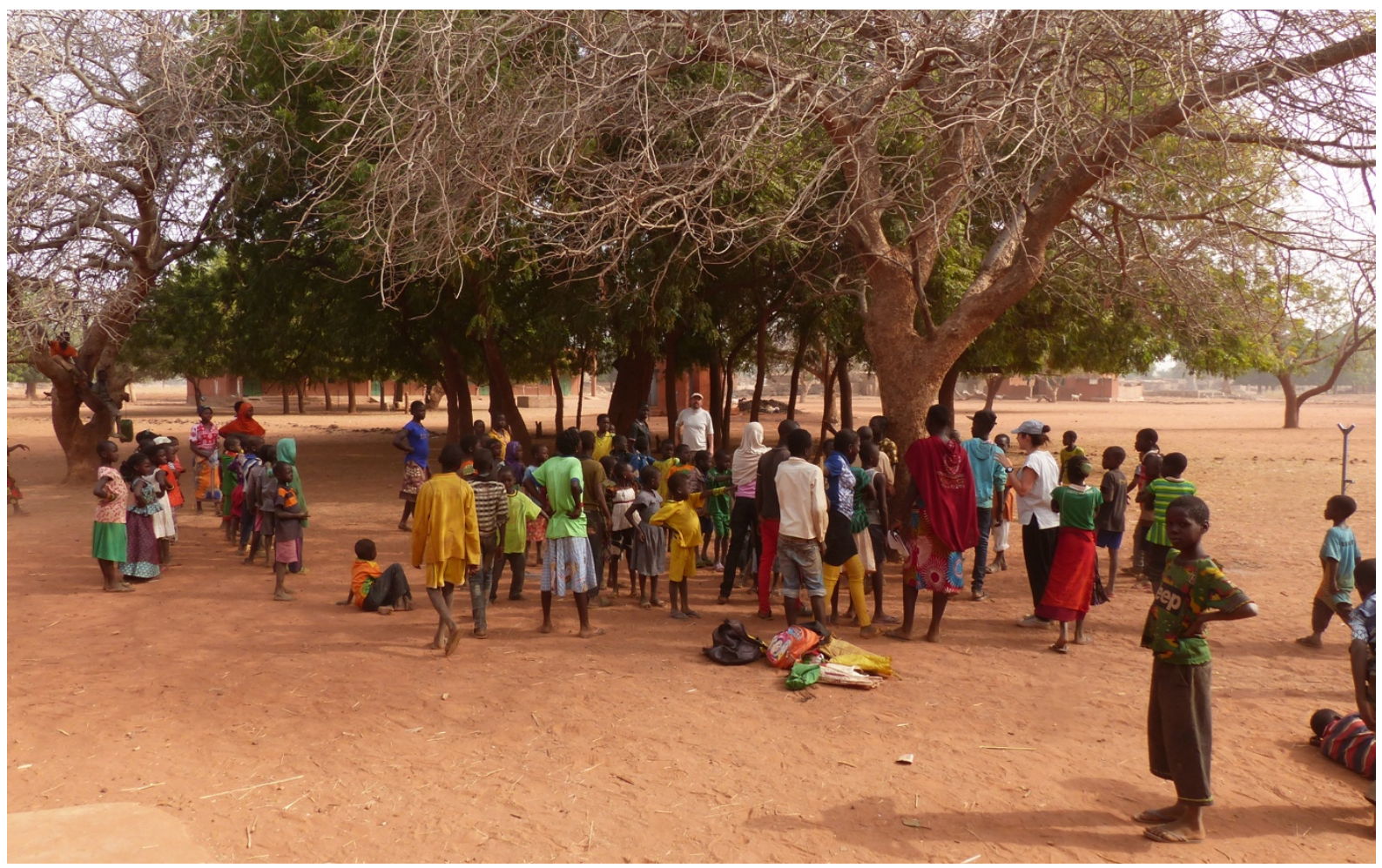

Figure 1. First workshop session. Explanation on the esplanade outside the primary school.

After this first general explanation, which was combined with a series of fiches with images, the following activities were carried out:

- In groups, the children looked for earth in the area in three different colours, and took it to the classroom for a brief explanation on the size of the grains of earth.

- The earth was then sifted to separate the grains by size and to carry out a simple identification of the different components of the earth.

- With the different types of Baasneere earth provided by the different groups and others prepared by the UPV team specifically for the workshop, the children painted a large mural on white cotton fabric which was later used to decorate one of the walls of the school.

- In the classroom, the children produced their own individual paintings using earth in different colours.

The children used this experience to explore the plastic potential of earth through different artistic activities such as the design of murals or small paintings with earth and their hands.

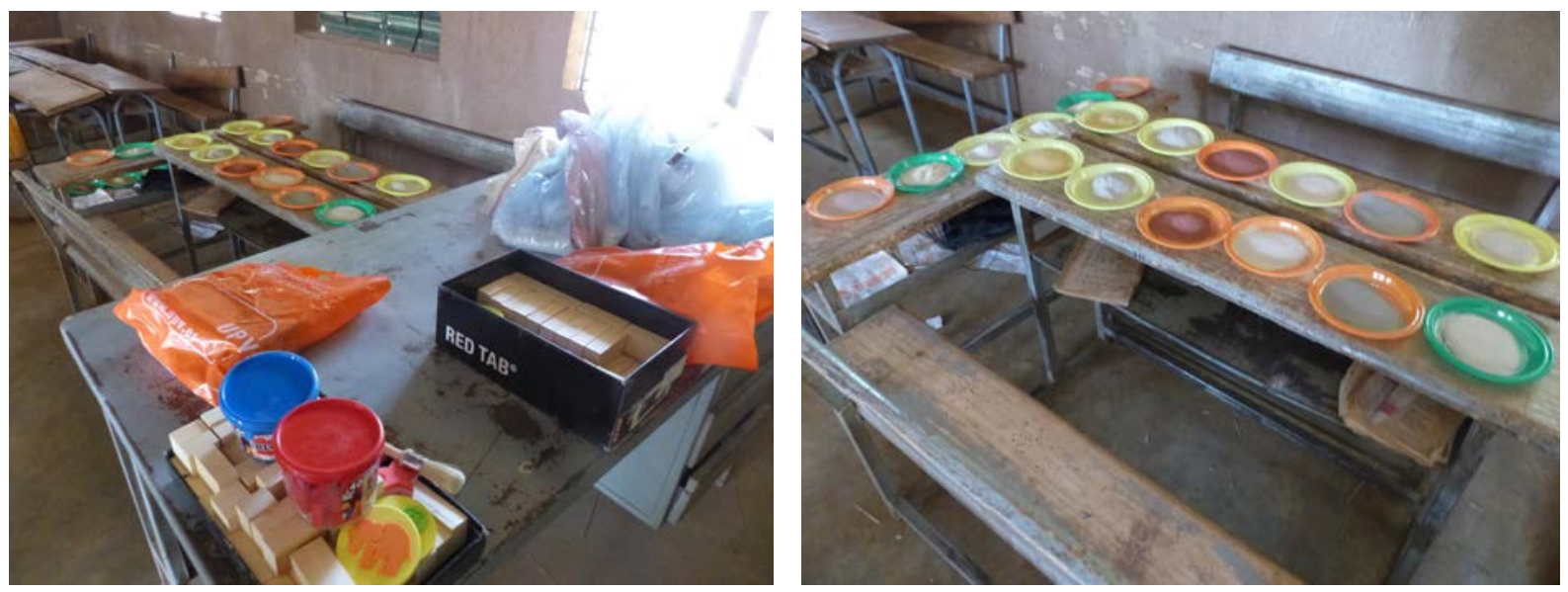

Figure 2. Preparation of different types of earth for artistic activity in the classroom. 


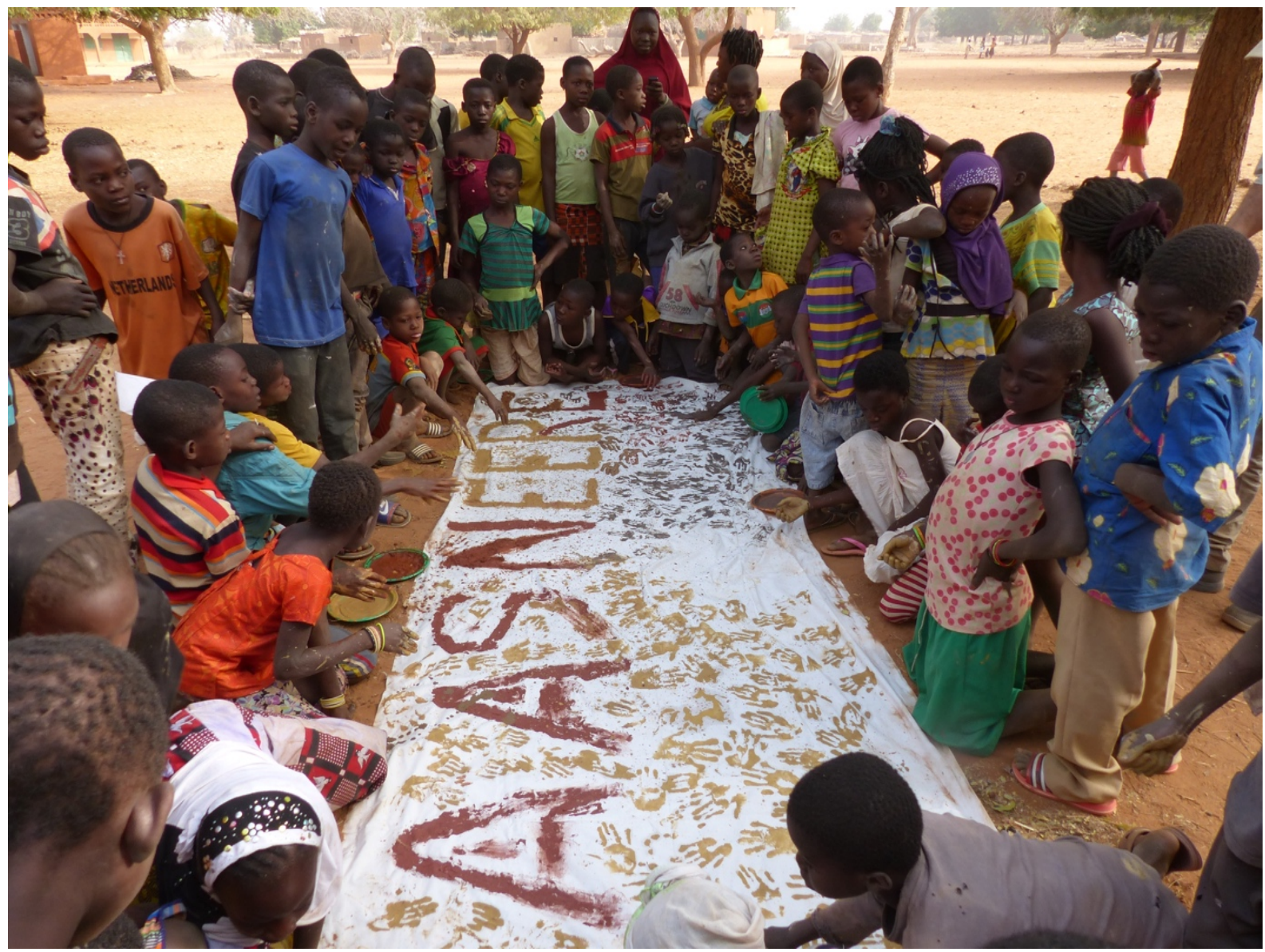

Figure 3. First workshop session. Painting of a mural by all the children in the workshop.
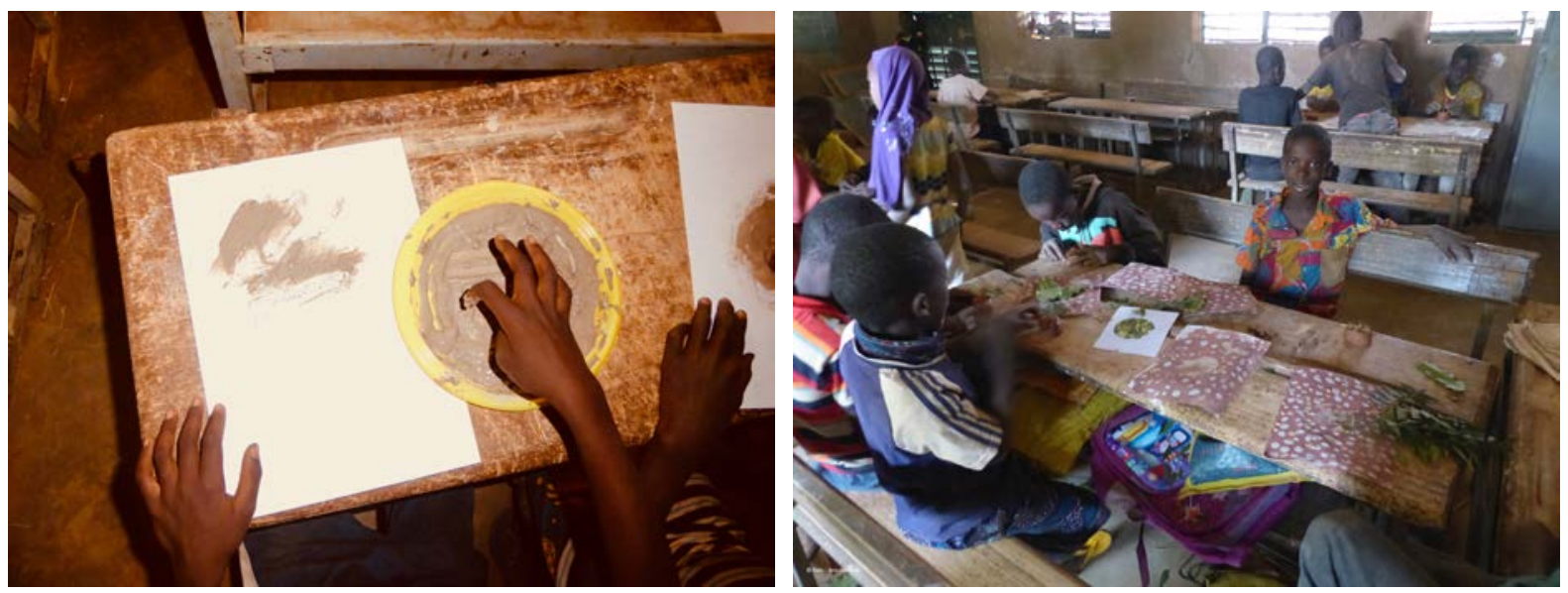

Figure 4. First workshop session. Individual painting with different colours of earth.

\subsection{Second workshop session}

In the second workshop session, the activities examined earth as a construction material. The session began with a brief explanation about the traditional houses from different parts of the world to show how traditional architecture is built using the local natural materials of each place. Different fiches were used to show houses from different places built using available materials (wood, stone, earth, etc...). The aim of this activity was to show the children why the buildings of their town were traditionally built with earth, using different games to simply show how this material can be used in construction. After an introductory explanation the activities prepared for the day began:

- A first game of bondings with small wooden blocks was played to show children how the new secondary school in Baasneere is being built. The aim of this exercise was to show how adobe 
blocks or CEBs are used in the same way, although the latter constitute an improvement on traditional adobe blocks.

- Small competition, searching for natural materials in Baasneere. For this activity the children were organized into groups and given cards with images of different materials. Each group was in charge of looking for the material on its photograph and taking it to the classroom to show to the other classmates. The aim was to find very simple materials that are easy to find in the town, such as small tree branches, leaves, small stones, straw ...

- Once each team had collected its materials, these were organized by colour, texture, and size and a small game was played where children had to try to identify each material with their eyes closed.

- Using the materials collected and modelling clay the children built models of small miniature houses and put some of the concepts explored into practice.
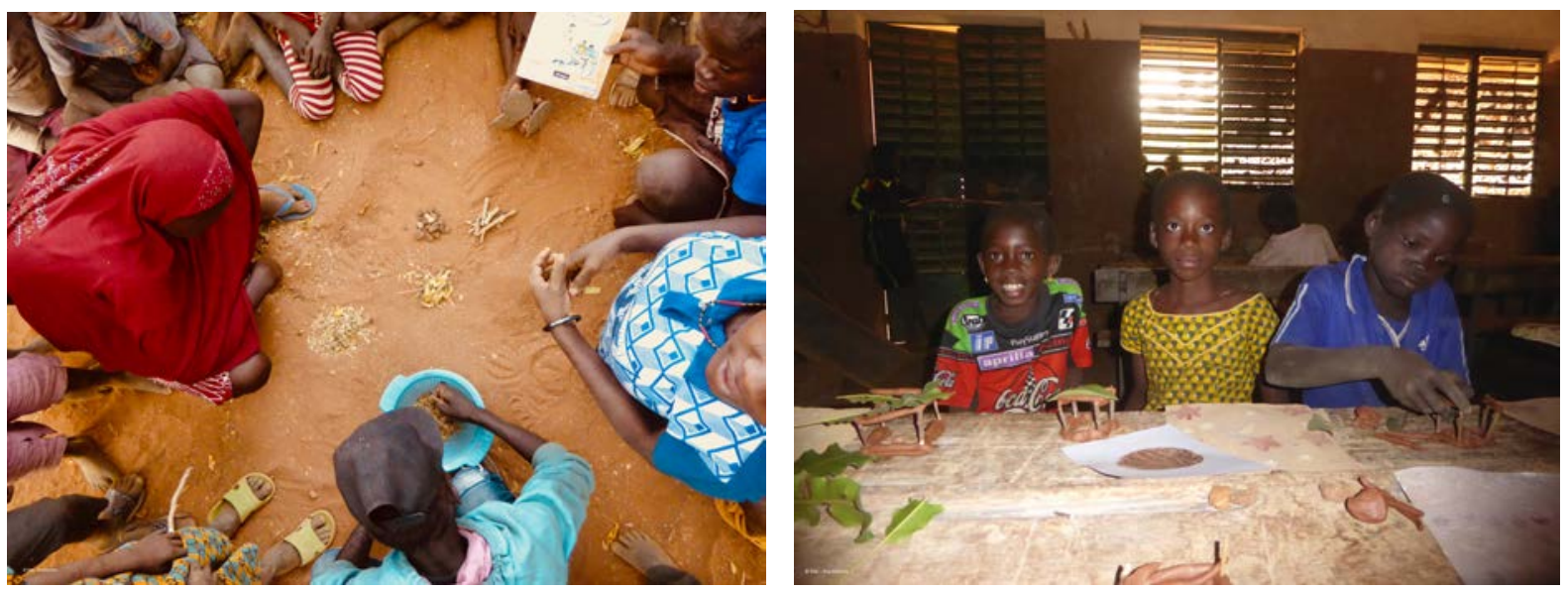

Figure 5. Second workshop session. Collection and preparation of the different materials and model construction workshop.
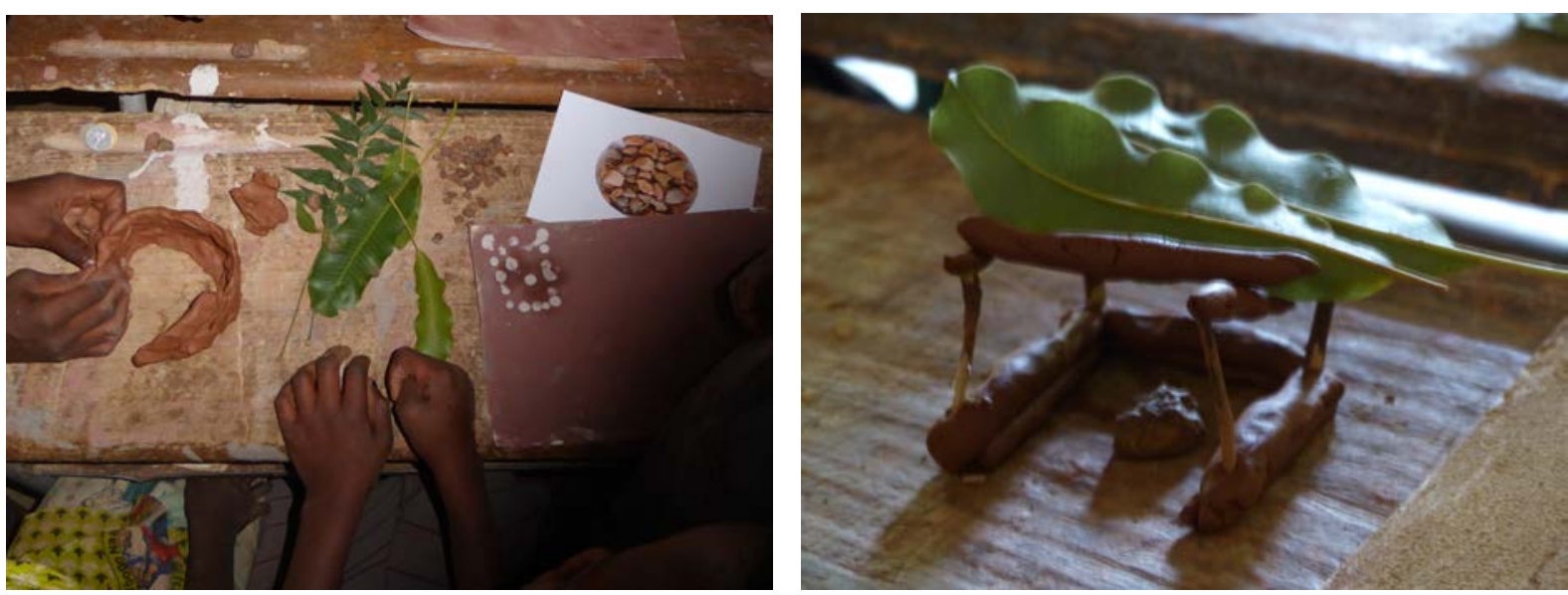

Figure 6. Second workshop session. Clay modelling and model construction using the materials collected.

The results of this workshop were excellent and models were obtained where the children had applied clear constructive concepts. Some models were built using moulded clay walls, clearly following the techniques of adobe or even cob walls. In other cases the clay was only used as the basis for a small wooden structure, with light plant roofs made to cover the space of the small model.

\section{CONCLUSION}

The activities developed with the local primary school children were designed to raise awareness on the value of their cultural identity, allowing them to work with creative skills (such as painting and modelling) which are not usually developed in the country's overcrowded schools. 
These dissemination activities with the younger members of the local population have been essential to the ConBurkina project. The aim of all these activities was to provide the children of Baasneere with knowledge which would reinforce their appreciation of their own culture while empowering the future generations, who in future will be in charge of decision-making in the face of changes imposed by industry, globalization, and speculation.

In addition, for the UPV team with its extensive experience in the execution of children's workshops, this experience was hugely challenging, both for the amount of children who took part in the workshop and for the difficulties in adapting these activities to a very specific local situation which differed greatly from their own, sometimes requiring changes to the programmed activities. Therefore, the activities carried out have been a learning experience not only for the children they were aimed at, but also for the team of researchers from the ConBurkina cooperation project.

\section{NOTE}

The work contained in this article is included in the research project "ConBurkina", funded by the ADSIDEO Programme of the Development Cooperation Center of the Universitat Politècnica de València.

\section{REFERENCES}

[1] Mileto, C.; Vegas López-Manzanares, F.; García-Soriano, L.; Gómez-Patrocinio, F. J. (2018). Research experiences in cooperation and sustainable development. The case of Baasneeré (Burkina Faso) in VIBRArch Valencia 1 Bienial Research of Architecture, October, 18-19 Valencia, Spain.

[2] Rama, V.; Dasaratha; Zlotkowski, E. A. Learning by Doing: Concepts and Models for ServiceLearning in Accounting. Washington, D.C.: American Association for Higher Education, 1998.

[3] Piaget, J. (1933), La representación del mundo en el niño, Morata Ed., Madrid, 9ª ed.

[4] Steiner, R. (1908), La educación del niño, Rudolf Steiner Ed., Madrid, $15^{\mathrm{a}}$ ed. 